\title{
THE GENERALIZED HYPERGEOMETRIC FUNCTION AND ASSOCIATED FAMILIES OF MEROMORPHICALLY MULTIVALENT FUNCTIONS
}

\begin{abstract}
M. K. AouF
Abstract. Making use a linear operator, which is defined here by means of the Hadamard product (or convolution) involving the generalized hypergeometric function, we introduce two novel subclasses $Q_{p, q, s}\left(\alpha_{1} ; A, B, \lambda\right)$ and $Q_{p, q, s}^{+}\left(\alpha_{1} ; A, B, \lambda\right)$ of meromorphically multivalent functions of order $\lambda(0 \leqslant \lambda<p)$ in the punctured disc $U^{*}$. In this paper we investigate the various important properties and characteristics of these subclasses of meromorphically multivalent functions. We extend the familiar concept of neighborhoods of analytic functions. We also derive many results for the Hadamard products of functions belonging to the class $Q_{p, q, s}^{+}\left(\alpha_{1} ; A, B, \lambda\right)$.
\end{abstract}

Mathematics subject classification (2000): 30C45.

Keywords and phrases: Generalized hypergeometric function, Hadamard product, meromorphic functions, neighborhoods.

\section{REFERENCES}

[1] O. Altintas AND S. OWa, Neighborhoods of certain analytic functions with negative coefficients, Internat. J. Math. Math. Sci., 19 (1996), 797-800.

[2] O. Altintas, O. OzKan AND H. M. SRIVASTAVA, Neighborhoods of a class of analytic functions with negative coefficients, Appl. Math. Lett., 13, 3 (2000), 63-67.

[3] O. Altintas, O. OzKAn AND H. M. SRIVASTAVA, Neighborhoods of a certain family of multivalent functions with negative coefficients, Comput. Math. Appl., 47 (2004), 1667-1672.

[4] M. K. Aouf, On a class of meromorphic multivalent functions with positive coefficients, Math. Japon., 35 (1990), 603-608.

[5] M. K. Aouf, A generalization of meromorphic multivalent functions with positive coefficients, Math. Japon., 35 (1990), 609-614.

[6] M. K. Aouf AND H. M. Hossen, New criteria for meromorphic p-valent starlike functions, Tsukuba J. Math., 17 (1993), 481-486.

[7] M. K. Aouf, H. M. Hossen And H. E. Elattar, A certain class of meromorphic multivalent functions with positive and fixed second coefficients, Punjab Univ. J. Math., 33 (2000), 115-124.

[8] J. DZIOK AND M. SRIVASTAVA, Classes of analytic functions associated with the generalized hypergeometric function, Appl. Math. Comput., 103 (1999), 1-13.

[9] J. DZIOK AND M. SRIVAstava, Certain subclasses of analytic functions associated with the generalized hypergeometric function, Integral Transform. Spec. Funct., 14 (2003), 7-18.

[10] A. Gangahharan, T. N. Shanamugam and H. M. SRivastava, Generalized hypergeometric functions associated with k-uniformly convex functions, Comput. Math. Appl., 44, 2 (2002), 15151526.

[11] A. W. Goodman, Univalent functions and nonanalytic curves, Proc. Amer. Math. Soc., 8 (1957), 598-601.

[12] I. S. JACK, Functions starlike and convex functions of order $\alpha$, J. London Math. Soc. (Ser. 2), 2, 3 (1971), 469-474.

[13] S. B. Joshi AND M. K. Aouf, Meromorphic multivalent functions with positive and fixed second coefficients, Kyungpook Math. J., 35 (1995), 163-169. 
[14] S. B. Joshi AND H. M. SRIVASTAVA, A certain family of meromorphically multivalent functions, Comput. Math. Appl., 38, 3-4 (1999), 201-211.

[15] S. R. KUlKaRni, U. H. NAIK AND H. M. SRIVASTAVA, A certain class of meromorphically p-valent quasi-convex functions, PanAmer. Math. J., 8, 1 (1998), 57-64.

[16] J. -L. LiU, Properties of some families of meromorphic p-valent functions, Math. Japon., 52, 3 (2000), 425-434.

[17] J. -L. LIU, Strongly starlike functions associated with the Dziok-Srivastava operator, Tamkang J. Math., 35, 1 (2004), 37-42.

[18] J. -L. LiU AND H. M. SRIVASTAVA, A linear operator and associated families of meromorphically multivalent functions, J. Math. Anal. Appl., 259 (2001), 566-581.

[19] J. -L. LIU AND H. M. SRIVASTAVA, Subclasses of meromorphically multivalent functions associated with a certain linear operator, Math. Comput. Modelling, 39 (2004), 35-44.

[20] J. -L. LiU AND H. M. SRIVASTAVA, Classes of meromorphically multivalent functions associated with the generalized hypergeometric function, Math. Comput. Modelling, 39 (2004), 21-34.

[21] M. L. Mogra, Meromorphic multivalent functions with positive coefficients. I, Math. Japon., 35, 1 (1990), 1-11.

[22] M. L. Morga, Meromorphic multivalent functions with positive coefficients. II, Math. Japon., 35, 6 (1990), 1089-1098.

[23] S. Owa, H. E. Darwish AND M. K. Aouf, Meromorphic multivalent functions with positive and fixed second coefficients, Math. Japon., 46, 2 (1997), 231-236.

[24] R. K. RAINA AND H. M. SRIVASTAVA, A new class of meromorphically multivalent functions with applications to generalized hypergeometric functions, Math. Comput. Modelling, 43 (2006), 350-356.

[25] St. Ruscheweyh, Neighborhoods of univalent functions, Proc. Amer. Math. Soc., 81 (1981), $521-$ 527.

[26] A. Schild And H. Silverman, Convolution of univalent functions with negative coefficients, Ann. Univ. Mariae Curie-Sklodowska Sect. A, 29 (1975), 99-107.

[27] H. M. SRivastava, H. M. Hossen, And M. K. Aouf, A unified presentation of some classes of meromorphically multivalent functions, Comput. Math. Appl., 38 (1999), 63-70.

[28] B. A. URalegaddi AND M. D. Ganigi, Meromorphic multivalent functions with positive coeffcients, Nepali. Math. Sci. Rep., 11, 2 (1986), 95-102.

[29] B. A. URAlegaddi AND C. Somanatha, Certain classes of meromorphic multivalent functions, Tamkang J. Math., 23 (1992), 223-231.

[30] D. -G. YANG, On new subclasses of meromorphic p-valent functions, J. Math. Res. Eposition, 15 (1995), 7-13.

[31] D. -G. YANG, Subclasses of meromorphic p-valent convex functions, J. Math. Res. Eposition, 20 (2000), 215-219. 